\title{
Determinants of near miss mortality in a tertiary care centre
}

\section{Sofia Abubekhar Suhurban, Bindu Nambisan*, Sujatha Thankappan Lekshmikutty, Mayadevi Brahmanandan, Sreekumary Radha}

Department of Obstetrics and Gynecology, Medical College, Trivandrum, Kerala, India

Received: 21 November 2016

Accepted: 13 December 2016

\section{*Correspondence:}

Dr. Bindu Nambisan,

E-mail: bindu.nambisan1971@gmail.com

Copyright: (C) the author(s), publisher and licensee Medip Academy. This is an open-access article distributed under the terms of the Creative Commons Attribution Non-Commercial License, which permits unrestricted non-commercial use, distribution, and reproduction in any medium, provided the original work is properly cited.

\begin{abstract}
Background: Near misses are defined as pregnant women with severe-life threatening conditions who nearly die but, with good care or good luck survive. Because near miss situation occurs more frequently than maternal death, more comprehensive and statistically reliable analysis could be conducted to assess the quality of maternal care and to develop evidence-based management protocols. The objectives of this study were to evaluate the determinants of near miss maternal mortality in a tertiary referral Government medical college hospital in Trivandrum, Kerala.

Methods: Case control study from a defined delivery population with three randomly selected pregnant women as controls for every case. Study was conducted at Department of Obstetrics and Gynecology, Medical College Hospital Trivandrum, Kerala, India. Study duration was one year. Study population were patients admitted in Obstetrics and Gynecology Department, fulfilling the WHO criteria of near miss.

Results: Of the primary determinant factors of near miss in this study, preeclampsia contributed the main role, followed by hemorrhage and eclampsia. During the antenatal period, preeclampsia was the major determinant followed by eclampsia. Hemorrhage was the major determinant in intra op /intra natal cases and next was eclampsia. Postpartum hemorrhage, eclampsia and preeclampsia were the major determinants in post-partum /post op cases. Among the associated indicators assessed, low socioeconomic status, anaemia, high body mass index, referral status, placenta praevia and caesarean section were statistically significant.

Conclusions: Detailed analysis of near miss cases helps in identifying risk factors. It helps in formulating preventive strategies, and helps us in tackling the delays in referral process.
\end{abstract}

Keywords: Determinants, Eclampsia, Hemorrhage, Morbidity, Near miss, Preeclampsia

\section{INTRODUCTION}

Maternal and child health care is one of the eight basic components of primary health care in the declaration of Alma Ata. ${ }^{1}$ Pregnancy is one of the important events in women's life but many times it can become dangerous for her life. Social determinants and the health system performance play a major role in the occurrence of maternal deaths. The fifth millennium development goal intended to improve maternal health and the target was to decrease the maternal mortality rate by $75 \%$ by $2015 .^{2}$
Maternal mortality ratio of Kerala is $66 .{ }^{3}$ While the estimated maternal mortality throughout the world is over half a million, approximately eight million women are suffering from serious pregnancy related complications every year. ${ }^{4}$ In India 60-70 thousand maternal death occur each year and possible 20-30 times that figure suffer from ill health and near misses, hence maternal health remains a huge challenge for the country. Sadly, every ten minutes a woman dies in India from pregnancy and complications of child birth. The concept of maternal near miss was defined by the World Health Organization 
(WHO) in 2009 as "a women who nearly died but survived a complication during pregnancy, child birth or within 42 days after termination of pregnancy., 5,6 Maternal mortality is frequently described as "Just The Tip of The Ice berg" alluding that there is a vast base to the ice berg in the form of maternal near miss(MNM) Advantages of investigating near miss events over events with fatal outcome are;

- Near misses are more common than maternal death

- They have the same pathways which lead to deaths and provide information regarding care received and possible means of prevention

- As the woman survives, near miss review may be seen as less threatening than the death reviews, for the teams who report them

- One can learn from the women themselves as they themselves are interviewed.

WHO recommended 3 different approaches of selection criteria for identification of maternal near miss cases. They are;

- Disease specific criteria

- Management based criteria, and

- Organ Dysfunction criteria.

Disease specific criteria was a clinical criteria related to a specific disease entity such as preeclampsia, eclampsia, HELLP syndrome, severe haemorrhage, severe sepsis and uterine rupture. ${ }^{7,8}$ These criteria had too low a threshold of morbidity to be called near miss and the most common direct cause of maternal mortality i.e. pulmonary embolism was omitted because of the difficulty of diagnosis. It also left out early pregnancy complication like ectopic pregnancy and abortions.

Intervention based criteria was used in most developed countries where admission to ICU or the requirement of critical care was used as the criteria to identify the near miss. ${ }^{9,10}$ The main disadvantage is that it is based on the resources available. The most obvious problem was the inaccessibility of intensive care beds for patients requiring them. The major reasons were, when death occurred before admission, the lack of availability of beds and the distance between the maternity unit and intensive care facilities. Moreover, admission criteria to intensive care units vary. Organ system dysfunction based criteria. ${ }^{11}$ This system is based on the concept that there is sequence of events leading from good health. The sequence is clinical insult, followed by a systemic inflammatory response syndrome (SIRS), organ dysfunction, organ failure and finally death. Near misses would be those women with organ dysfunction and organ failures who survive. The presence of any one of the markers in pregnancy from conception to forty-two days post-delivery constitutes a near miss. Having identified the case, the primary obstetric cause can then be identified and classified. This system allows for identification of all critically ill women and allows for the identification of new and emerging disease priorities. The WHO technical working group recommends that this new maternal near miss approach can be adopted by all countries. Applying this approach will also help to identify the health system shortfalls that countries need to address to reduce complications and fatal outcomes of pregnancy and child birth. This system has several advantages which includes

- Establishing the pattern of diseases causing morbidity and their relative importance

- Comparisons can be made; definition can be standardized and used in many different settings

- Health system is not a part of the definition so problems within the health system can be studied

- Cases can be flagged when they occur as a function of an ongoing audit making it a virtually prospective audit, avoiding the problem of poor recording.

Some of the disadvantages is that it is dependent on a minimum level of care in a country. There must be functioning laboratories for some specific blood test and basic critical care monitoring must be available. Retrospective identification of cases is very difficult because of the inability to identify cases from registers. Diagnostic criteria of severe maternal morbidity have been advocated by Waterstone et al, Mantel et al, and the WHO. In this study the WHO organ dysfunction criteria 2008 has been used as a study tool. WHO organ dysfunction criteria are broadly classified as cardiovascular, respiratory, renal, hepatic, coagulation, neurological and uterine dysfunctions. Cardiovascular dysfunction includes shock, cardiac arrest, severe hypoperfusion, severe acidosis $(\mathrm{pH}<7.1)$, use of continuous vasoactive drugs, and cardiopulmonary resuscitation.

Respiratory dysfunction includes acute cyanosis,gasping, severe tachypnoea $>40$ breaths/mt, severe bradypnoea $<6$ breaths/mt, severe hypoxaemia, intubation and ventilation not related to anaesthesia. Renal dysfunction includes oliguria not responsive to fluids or diuretics, severe acute azotemia (creatinene $>3.5 \mathrm{mg} / \mathrm{dl}$ ), dialysis for acute renal failure. Hepatic dysfunction includes jaundice in presence of preeclampsia, and severe acute hyperbilirubinemia with serum bilirubin levels $>6 \mathrm{mg} / \mathrm{dl}$. Coagulation dysfunction includes failure to form clots, thromboctytopenia with platelet counts $<50000$, massive transfusion of blood or red cell $>4$ units.

Neurological dysfunction includes prolonged unconsciousness or coma lasting $>12$ hours, stroke, uncontrolled status epilepticus, and global paralysis. Uterine dysfunction includes hysterectomy due to uterine infection or haemorrhage.

\section{METHODS}

Case control study from a defined delivery population with three randomly selected pregnant women as controls 
for every case. Study conducted in Department of Obstetrics and Gynecology, Medical College Hospital Trivandrum, Kerala. On year study duration Study with patients admitted in Obstetrics and Gynecology Department, fulfilling the WHO criteria of near miss. Cases defined as "a women who nearly died but survived a complication that occurred during pregnancy, childbirth or within 42 days of termination of pregnancy." Controls were selected randomly (three women who delivered subsequent to the case not satisfying criteria case definition).

\section{Exclusion criteria}

Those women who did not give consent for the study. Sample size calculated using the following assumptions:

- $\quad$ Confidence level $=95 \%$

- $\quad$ Type 1 error $=5 \%$

- $\quad$ Type 2 error $=20 \%$
- $\quad$ Power $=80 \%$

- $\quad$ Ratio of case to control $=1: 3$

- Odds ratio $=2.5$

- Expected frequency of exposure in control $=8 \%$

- Sample size using software EPI INFO was found to be 125 cases and 375 controls.

\section{RESULTS}

\section{Age distribution}

$48.8 \%$ of the cases were in the age group $<25$ years, as compared to $43.5 \%$ among controls. The groups were comparable.

\section{Socio economic status}

$85.6 \%$ of the cases belonged to low socioeconomic group as compared to $66.1 \%$ of the controls, which was found to be statistically significant (Table 1).

Table 1: Socioeconomic status.

\begin{tabular}{|c|c|c|c|c|c|c|}
\hline \multirow{3}{*}{ SES } & \multicolumn{4}{|c|}{ Category } & \multirow{2}{*}{\multicolumn{2}{|c|}{ Total }} \\
\hline & \multicolumn{2}{|c|}{ Case } & \multicolumn{2}{|c|}{ Control } & & \\
\hline & $\mathbf{N}$ & $\%$ & $\mathbf{N}$ & $\%$ & $\mathbf{N}$ & $\%$ \\
\hline Lower & 107 & 85.6 & 248 & 66.1 & 355 & 71 \\
\hline Upper & 18 & 14.4 & 127 & 33.9 & 145 & 29 \\
\hline Total & 125 & 100 & 375 & 100 & 500 & 100 \\
\hline
\end{tabular}

$\chi^{2}=17.254 ; \mathrm{df}=1 ; \mathrm{p}<0.001 ; \mathrm{OR}=3.716 ; 95 \% \mathrm{CI}=(1.370-10.079)$.

Table 2: Indications for admission.

\begin{tabular}{|c|c|c|c|c|c|c|}
\hline \multirow{3}{*}{ Indication for admission } & \multicolumn{4}{|c|}{ Category } & \multirow{2}{*}{\multicolumn{2}{|c|}{ Total }} \\
\hline & \multicolumn{2}{|c|}{ Case } & \multicolumn{2}{|c|}{ Control } & & \\
\hline & $\mathbf{N}$ & $\%$ & $\mathbf{N}$ & $\%$ & $\mathbf{N}$ & $\%$ \\
\hline Uncontrolled hypertension & 20.0 & 16.0 & 15.0 & 4.0 & 35.0 & 7.0 \\
\hline HELLP & 3.0 & 2.4 & 0.0 & 0.0 & 3.0 & 0.6 \\
\hline Severe preeclampsia & 7.0 & 5.6 & 6.0 & 1.6 & 13.0 & 2.6 \\
\hline Eclampsia & 29.0 & 23.2 & 0.0 & 0.0 & 29.0 & 5.8 \\
\hline Antepartum haemorrhage & 13.0 & 0.4 & 11.0 & 2.9 & 24.0 & 4.8 \\
\hline Postpartum haemorrhage & 16.0 & 12.8 & 0.0 & 0.0 & 16.0 & 3.2 \\
\hline Diabetes mellitus & 4.0 & 3.2 & 2.0 & 0.5 & 6.0 & 1.2 \\
\hline Thrombocytopenia & 4.0 & 3.2 & 1.0 & 0.3 & 5.0 & 1.0 \\
\hline Pulmonary embolism & 2.0 & 1.6 & 0.0 & 0.0 & 2.0 & 0.4 \\
\hline Term complicated & 10.0 & 8.0 & 223.0 & 59.5 & 233.0 & 46.6 \\
\hline Fever & 2.0 & 1.6 & 1.0 & 0.3 & 3.0 & 0.6 \\
\hline Dyspnoea & 6.0 & 4.8 & 1.0 & 0.3 & 7.0 & 1.4 \\
\hline Hypotension & 1.0 & 0.8 & 0.0 & 0.0 & 1.0 & 0.2 \\
\hline Intrauterine demise & 4.0 & 3.2 & 6.0 & 1.6 & 10.0 & 2.0 \\
\hline Fetal distress & 1.0 & 0.8 & 9.0 & 2.4 & 10.0 & 2.0 \\
\hline Uterine inversion & 1.0 & 0.8 & 0.0 & 0.0 & 1.0 & 0.2 \\
\hline PPROM & 2.0 & 1.6 & 22.0 & 5.9 & 24.0 & 4.8 \\
\hline PROM & 0.0 & 0.0 & 30.0 & 8.0 & 30.0 & 6.0 \\
\hline IUGR, Oligamnios & 0.0 & 0.0 & 16.0 & 4.3 & 16.0 & 3.2 \\
\hline Labour pain & 0.0 & 0.0 & 32.0 & 8.5 & 32.0 & 6.4 \\
\hline Total & 125.0 & 100.0 & 375.0 & 100.0 & 500.0 & 100.0 \\
\hline
\end{tabular}




\section{Parity}

$64 \%$ of the cases were primigravida, as compared to $53.6 \%$ among controls. $36 \%$ of the cases and $46.4 \%$ of controls were multigravida.

\section{Booking status}

$77.6 \%$ of the cases were referred as compared to $29.3 \%$ of the controls, which was found to be statistically significant (OR 3.202).

\section{Admission status}

$88.8 \%$ of the cases were emergency admissions as compared to $37.1 \%$ of the controls, which was statistically significant.

\section{Time of admission}

$67.2 \%$ of the cases were admitted during antenatal period

\section{Indication for admission}

Indications for admission are mentioned in (Table 2).

\section{Body mass index}

$33.6 \%$ of the cases were overweight or obese as compared to $9.6 \%$ of the controls, which was statistically significant (OR 4.77).

\section{History of adverse pregnancy outcome}

$5.6 \%$ of cases and $5.1 \%$ of control group had a history of adverse pregnancy outcome.

\section{Presence of hypertension}

$53.6 \%$ of the cases were hypertensive as compared to $22.1 \%$ of the controls, which was found to be statistically significant (OR 4.06). Preeclampsia was seen in $33.8 \%$ of the cases as compared to $29.3 \%$ of the controls.

\section{Presence of diabetes}

$18.5 \%$ of the cases had diabetes as compared to $16.5 \%$ of the controls. This was not found to be statistically significant.

\section{Presence of anaemia}

$64 \%$ of the cases had anaemia as compared to $42.9 \%$ of the controls, which was statistically significant.

\section{Presence of cardiac disease}

This was comparable amongst cases and controls.

\section{Other medical disorders}

There was one case each of autoimmune disease and renal disorder and no case of viral hepatitis

\section{Presence of placenta praevia}

$15.2 \%$ of the cases had placenta praevia as compared to $11 \%$ of the controls, which was statistically significant. (OR 5.93).

\section{Presence of $\mathrm{APH}$}

$13.6 \%$ had APH as compared to $2.9 \%$ of the controls, which was found to be statistically significant (OR 5.21).

\section{High total WBC count}

$28.8 \%$ of the cases had abnormal total count as compared to $0.3 \%$ of the controls which was found to be highly statistically significant (Table 3 ).

\section{Induction statistics}

$53.8 \%$ of the cases were induced as compared to $58.9 \%$ of the controls which was comparable.

Table 3: Total WBC count amongst cases and controls.

\begin{tabular}{|c|c|c|c|c|c|c|}
\hline \multirow{3}{*}{ Total count } & \multicolumn{4}{|c|}{ Category } & \multirow{2}{*}{\multicolumn{2}{|c|}{ Total }} \\
\hline & \multicolumn{2}{|c|}{ Case } & \multicolumn{2}{|c|}{ Control } & & \\
\hline & $\mathbf{N}$ & $\%$ & $\mathbf{N}$ & $\%$ & $\mathbf{N}$ & $\%$ \\
\hline Abnormal & 36.0 & 28.8 & 1.0 & 0.3 & 37 & 7.4 \\
\hline Normal & 89.0 & 71.2 & 374.0 & 99.7 & 463 & 92.6 \\
\hline Total & 125.0 & 100.0 & 375.0 & 100.0 & 500.0 & 100.0 \\
\hline
\end{tabular}

$\chi^{2}=111.387 ; \mathrm{df}=1 ; \mathrm{p}<0.001$ (Yates correction); $\mathrm{OR}=151 ; 95 \% \mathrm{CI}=20.455-1118$.

\section{Type of delivery}

66. $4 \%$ of the cases had caesarean sections as compared to $36.3 \%$ of the controls. In the cases group the major contributors were fetal distress, severe preeclampsia with failed induction and previous CS with placenta praevia \pm accreta whereas in the control group the major cause was previous CS followed by fetal distress. 


\section{Major dysfunction}

Major dysfunction noted was coagulatory dysfunction in 62 cases $(49.6 \%)$ followed by neurological dysfunction in 22 cases $(17.6 \%)$.

Hepatic dysfunction was seen in 19 cases (15.2\%), uterine dysfunction in 10 cases (8\%), respiratory dysfunction in 6 cases $(4.8 \%)$, cardiovascular dysfunction in 3 cases $(4 \%)$ and renal dysfunction in 1 case $(0.8 \%)$ (Table 4).
Table 4: WHO organ dysfunction classification.

\begin{tabular}{|lll|}
\hline WHO criteria & Frequency & Percentage \\
\hline $\begin{array}{l}\text { Cardiovascular } \\
\text { dysfunction }\end{array}$ & 5.0 & 4.0 \\
\hline Respiratory dysfunction & 6.0 & 4.8 \\
\hline Renal dysfunction & 1.0 & 0.8 \\
\hline Coagulation dysfunction & 62.0 & 49.6 \\
\hline Hepatic dysfunction & 19.0 & 15.2 \\
\hline Neurological dysfunction & 22.0 & 17.6 \\
\hline Uterine dysfunction & 10.0 & 8.0 \\
\hline Total & 125.0 & 100.0 \\
\hline
\end{tabular}

Table 5: Maternal complications.

\begin{tabular}{|c|c|c|c|c|c|c|c|c|}
\hline Complications & Cardiovascular & Respiratory & Renal & Coagulation & Hepatic & Neurological & Uterine & Total \\
\hline Eclampsia & & & & & & 22 & & 22 \\
\hline Severe preeclapsia & & & & 20 & 19 & & & 39 \\
\hline $\mathrm{PPH}$ & 1 & & & 27 & & & 10 & 38 \\
\hline Sepsis & & 2 & & 1 & & & & 3 \\
\hline Pulm embolism & 1 & 3 & & & & & & 4 \\
\hline Cardiac failure & 2 & 1 & & & & & & 3 \\
\hline Thrombocytopenia & & & & 4 & & & & 4 \\
\hline Hypotension & 1 & & & & & & & 1 \\
\hline Abruption & & & & 10 & & & & 10 \\
\hline Renal disease & & & 1 & & & & & 1 \\
\hline Total & 5 & 6 & 1 & 62 & 19 & 22 & 10 & 125 \\
\hline
\end{tabular}

Table 6: Time of near miss.

\begin{tabular}{|lllll|}
\hline WHO criteria & Antenatal & Intrapartum/intraop & Postpartum/postop & Total \\
\hline Cardiovascular dysfunction & 1 & 1 & 3 & 5 \\
\hline Respiratory dysfunction & & & 6 & 6 \\
\hline Renal dysfunction & 1 & 17 & 26 & 1 \\
\hline Coagulation dysfunction & 19 & & 3 & 62 \\
\hline Hepatic dysfunction & 16 & 5 & 11 & 19 \\
\hline Neurological dysfunction & 6 & 9 & 1 & 22 \\
\hline Uterine dysfunction & & 32 & 50 & 10 \\
\hline Total & 43 & & & 125 \\
\hline
\end{tabular}

\section{Determinants of near miss}

It's seen that preeclampsia was the major determinant $(31.2 \%)$ followed by haemorrhage $(30.4 \%)$. Others were eclampsia (17.6\%), abruption (8\%), pulmonary embolism $(3.2 \%)$, sepsis $(2.4 \%)$, cardiac failure $(2.4 \%)$, thrombocytopenia $(3.2 \%)$, hypotension and renal disease. (Table 5).

\section{Time of occurrence of near miss}

Maternal near miss cases of $40 \%$ (50 cases) occurred in postnatal/post op phase, $34.4 \%$ (43 cases) occurred in antenatal phase and $25.6 \%$ (32 cases) in intra partum/intra op phase (Table 6).

\section{Determinants leading to near miss}

It's seen that the major determinant leading to near miss in antepartum period was severe preeclampsia about 31 cases $(72.09 \%)$ of which 15 cases lead to coagulatory dysfunction and 16 cases to hepatic dysfunction. 2nd major determinant was eclampsia about 6 cases $(13.95 \%)$ leading to neurological dysfunction. There were 4 cases of thrombocytopenia ( 2 cases due to dengue fever, 2 cases due to gestational thrombocytopenia) leading to coagulatory dysfunction. There was 1 case of ventricular tachycardia leading to ventricular fibrillation. There was 1 case of bilateral renal calculus and ureteric calculus with obstructive hydronephrosis leading to renal dysfunction (Table 7). 
Table 7: Near miss determinants amongst antenatal cases.

\begin{tabular}{|c|c|c|c|c|c|c|c|}
\hline Complications & Cardiovascular & Respiratory & Renal & Coagulation & Hepatic & Neurological Uterine & Total \\
\hline Eclampsia & & & & & & 6 & 6 \\
\hline Severe preeclampsia & & & & 15 & 16 & & 31 \\
\hline \multicolumn{8}{|l|}{ PPH } \\
\hline \multicolumn{8}{|l|}{ Sepsis } \\
\hline \multicolumn{8}{|l|}{ Pulm embolism } \\
\hline Cardiac failure & 1 & & & & & & 1 \\
\hline Thrombocytopenia & & & & 4 & & & 4 \\
\hline \multicolumn{8}{|l|}{ Hypotension } \\
\hline \multicolumn{8}{|l|}{ Abruption } \\
\hline Renal disease & & & 1 & & & & 1 \\
\hline Total & 1 & & 1 & 19 & 16 & 6 & 43 \\
\hline
\end{tabular}

Table 8: Near miss determinants amongst intrapartum and intraop cases.

\begin{tabular}{|c|c|c|c|c|c|}
\hline Complications Cardiovascular & Respiratory Renal & Coagulation Hepatic & Neurological & Uterine & Total \\
\hline Eclampsia & & & 5 & & 5 \\
\hline Severe preeclampsia & & 3 & & & 3 \\
\hline PPH & & 4 & & 9 & 13 \\
\hline \multicolumn{6}{|l|}{ Sepsis } \\
\hline Pulm embolism 1 & & & & & 1 \\
\hline \multicolumn{6}{|l|}{ Cardiac failure } \\
\hline \multicolumn{6}{|l|}{ Thrombocytopenia } \\
\hline \multicolumn{6}{|l|}{ Hypotension } \\
\hline Abruption & & 10 & & & 10 \\
\hline \multicolumn{6}{|l|}{ Renal disease } \\
\hline Total & & 17 & 5 & 9 & 32 \\
\hline
\end{tabular}

Table 9: Near miss determinants amongst post-partum/post op cases.

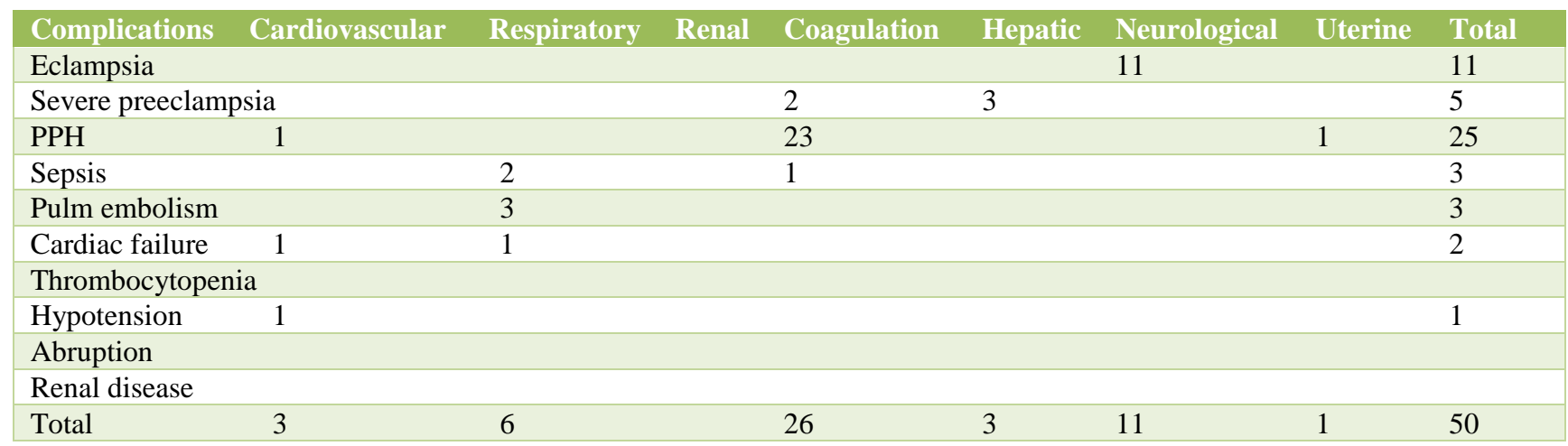

The major determinants leading to near miss in intrapartum/ intraop cases was haemorrhage (13 cases). 9 cases were due to placenta accreta and 4 cases due to PPH followed by abruption (10 cases). The third determinant was intra partum eclampsia leading to neurological dysfunction. There was one case each of sepsis and pulmonary embolism (Table 8). The major determinant in postpartum/post op cases was PPH in 25 cases $(50 \%)$ followed by eclampsia in 11 cases $(22 \%)$, pre-eclampsia in 5 cases, sepsis in 3 cases, pulmonary embolism in 3 cases, cardiac failure in 2 cases and hypotension (post spinal anaesthesia) in 1 case (Table 9).

\section{Duration of hospital stay}

$49.6 \%$ of the cases were admitted for $2-3$ weeks. Only $2 \%$ of "controls" had this duration of stay.

\section{Analysis}

Variables which were found to have significant association with near miss during univariate analysis with $\mathrm{p}$ value $<0.05$ were subjected to multivariate analysis of binary logistic regression. Binary logistic regression found that socioeconomic status, referred status, anaemia, hypertension, high body mass index, and placenta praevia were significant predictors of near miss in this study. (Table 10, 11). 
Table 10: Univariate analysis.

\begin{tabular}{|c|c|c|c|c|c|c|c|c|c|c|}
\hline & \multicolumn{2}{|c|}{ Case(N=125) } & \multicolumn{2}{|c|}{$\begin{array}{l}\text { Control } \\
(\mathbf{N}=375)\end{array}$} & \multicolumn{2}{|c|}{$\begin{array}{l}\text { Total } \\
(\mathbb{N}=500)\end{array}$} & \multirow[t]{2}{*}{ Chi } & \multirow[t]{2}{*}{ p } & \multirow[t]{2}{*}{ OR } & \multirow[t]{2}{*}{$95 \%$ CI for OR } \\
\hline & $\mathbf{N}$ & $\%$ & $\mathbf{N}$ & $\%$ & $\mathbf{N}$ & $\%$ & & & & \\
\hline SES (Lower) & 107 & 85.6 & 248 & 66.1 & 355 & 71 & 17.3 & 0.000 & 3.04 & $1.768-5.24$ \\
\hline Primi & 80 & 64 & 201 & 53.6 & 281 & 56.2 & 4.12 & 0.042 & 1.54 & $1.013-2.34$ \\
\hline Referred & 97 & 77.6 & 110 & 29.3 & 207 & 41.4 & 90 & 0.000 & 8.35 & $5.187-13.4$ \\
\hline Anaemia & 80 & 64 & 161 & 42.9 & 241 & 48.2 & 16.7 & 0.000 & 2.36 & $1.555-3.59$ \\
\hline Hypertension & 67 & 53.6 & 83 & 22.1 & 150 & 30 & 44.2 & 0.000 & 4.06 & $2.65-6.23$ \\
\hline Overweight & 42 & 33.6 & 36 & 9.6 & 78 & 15.6 & 41 & 0.000 & 4.77 & $2.874-7.9$ \\
\hline APH & 17 & 13.6 & 11 & 2.9 & 28 & 5.6 & 20.2 & 0.000 & 5.21 & $2.368-11.5$ \\
\hline $\begin{array}{l}\text { Abnormal total } \\
\text { count }\end{array}$ & 36 & 28.8 & 1 & 0.3 & 37 & 7.4 & 111 & 0.000 & 151 & 20465-1118 \\
\hline Placenta praevia & 19 & 15.2 & 11 & 2.9 & 30 & 6 & 25 & 0.000 & 5.93 & $2.737-12.9$ \\
\hline
\end{tabular}

Table 11: Bivariate analysis.

\begin{tabular}{|lllllll|}
\hline & B & S. E. & P & OR & \multicolumn{2}{c|}{ 95\% CI for OR } \\
\hline SES & & & & & Lower & Upper \\
\hline Primi & 0.998 & 0.332 & 0.003 & 2.713 & 1.414 & 5.205 \\
\hline Booking status & 0.149 & 0.269 & 0.580 & 1.161 & 0.685 & 1.967 \\
\hline Anaemia & 1.845 & 0.269 & $<0.001$ & 6.328 & 3.735 & 10.721 \\
\hline Hypertension & 0.889 & 0.264 & 0.001 & 2.434 & 1.450 & 4.086 \\
\hline Abn BMI & 1.360 & 0.270 & $<0.001$ & 3.896 & 2.295 & 6.613 \\
\hline Placenta praevia & 1.223 & 0.319 & $<0.001$ & 3.397 & 1.819 & 6.343 \\
\hline Constant & 1.916 & 0.486 & $<0.001$ & 6.793 & 2.618 & 17.625 \\
\hline
\end{tabular}

\section{DISCUSSION}

Maternal mortality rate in developing regions is 14 times higher than developed regions. Promotion of maternal nutrition and health education, with greater attention to emergency obstetric care at the district, sub centre and primary health care centre levels must be prioritized. ${ }^{12}$ New indicators have been developed for evaluating maternal health issues more effectively and thus the concept of maternal near miss has been explored as an adjunct to maternal death confidential enquiries13.The lack of a uniform, standardized, and reproducible definition of maternal morbidity as well as the difficulty associated with ascertaining and measuring maternal morbidity has been a major challenge in research. Pregnancy and child birth can move from normal pregnancy to being complicated (acute maternal morbidity) and to becoming life threatening, referred to as "near-miss" cases. (WHO 2004). ${ }^{14}$

India contributes to one-fourth of all maternal deaths globally. Of the primary determinant factors of near miss in this study, preeclampsia contributed the main role, followed by hemorrhage and eclampsia. In the antenatal period, preeclampsia was the major determinant followed by eclampsia. Hemorrhage was the major determinant in intra op /intra natal cases and next was eclampsia. Postpartum hemorrhage, eclampsia and preeclampsia were the major determinants in post-partum /post op cases This is in agreement with the FOGSI study which was a 3 year retrospective observational study from January 2005 to December 2007 in India as a whole, where the leading cause of maternal death was hypertensive disorders in pregnancy 15 followed by hemorrhage. Fourth determinant in this study was abruption.

A prospective study was conducted by Adeoye IA et al in a tertiary health care facility to identify the factors associated with maternal miss. ${ }^{14}$ This study also found that the referral status of women was a major determinant. Women who were referred from another facility had a fourfold risk $(\mathrm{OR}=3.84)$ of experiencing near miss as compared to those who were not referred, the probable reason being late referrals. In this study also referred cases constituted $77.6 \%$ of the cases.

The incidence of caesarean section amongst cases was high $(67.2 \%)$ and it is possible that the principal determinant of this rate was the severe morbidity itself, since the rate of caesarean sections was significantly higher in the women who developed severe morbidity during pregnancy compared to those who developed it during the peurperium. In this study $64 \%$ of the cases were primigravida. In this study, it did not emerge as a significant risk factor. In a cross sectional study conducted by Morse $\mathrm{MH}$ et al in regional reference 
hospital $33.7 \%$ of the cases were primigravida. ${ }^{15,16}$ Another study by Roopa $\mathrm{P}$ et al in tertiary Hospital at Karnataka found that primigravidae were more in near miss group. ${ }^{17}$ In an audit inducted by Prem D'Chunha in Father Muller Hospital, a tertiary level hospital showed that most common age group for near miss was 20-30 years as in this study.

Among the associated indicators assessed, anaemia and caesarean section were important. In this study anaemia was seen in $64 \%$ of the cases. A study conducted by and Goffman et al 18 in Dealer Hospital of the Albert Einstein College of Medicine found that obesity (BMI >29) was significantly associated with near miss. In our study BMI>24.5 was statistically significant. Ten women in our study underwent obstetric hysterectomies of which nine cases were due to placenta accreta and one case was due to secondary PPH. This is in agreement with the case control study conducted by Knight et al and Jennifer $\mathbf{J}$ et al in UK where they noted that both uterine rupture and placenta accreta were strongly associated with peripartum hysterectomy risk.

The limitation in this study was that our institution being a referral institution, the correct information regarding the number of antenatal visits could not be obtained and the "delays" in referral could not be verified in each referred patient.

\section{Recommendations}

- Based on this study the measures that can be taken to prevent near miss are;

- Improving antenatal care to help early identification of high risk pregnancies especially pre-eclampsia;

a. Detection of urine albumin should be a routine investigation in all hypertensive patients

b. All health care personnel should be made aware regarding preeclampsia and the importance of detecting proteinuria.

- Correcting anaemia in the antenatal period itself

- Raising the awareness in patients about hypertension and its complication and the need for regular follow up

- Developing protocols to prevent /manage PPH including the awareness about using active management during third stage of labour. Management protocol for obstetric hemorrhage in the form of "PPH Drill" should be displayed all labour rooms

- Training obstetric health professional in managing infrequent but fatal condition like sepsis

- Strengthening the peripheral health centres and timely referral system

- A multidisciplinary approach in patient management where facilities exist.

\section{CONCLUSION}

In this case control study, it is seen that the variables that were found to be significantly associated with near miss were, low socio economic status, referred cases, anaemia, hypertension, over weight $(\mathrm{BMI}>24.9)$ and placenta praevia. The major determinants leading to near miss were pre-eclampsia, haemorrhage, eclampsia, and abruption. Cases of pulmonary embolism, thrombocytopenia due to dengue fever and gestational thrombocytopenia, Sepsis, Cardiac failure, hypotension and renal disease were also noted. Detailed analysis of such cases would throw some light on preventive strategies, and also help us in tackling the "delays" in referral process.

Funding: No funding sources

Conflict of interest: None declared

Ethical approval: The study was approved by the Institutional Ethics Committee

\section{REFERENCES}

1. Chan M. Return to Alma-Ata. The Lancet. 2008;372:865-6.

2. Maternal mortality in India Special Bulletin 2007-2009, Office of the Registrar general of India. New Delhi. Ministry of Home affairs; 2011.

3. WHO. Maternal mortality in 1995: Estimates developed by WHO, UNICEF, UNFPA. World Health Organization, Geneva; 2001.

4. Say L, Souza JP, Pattinsons RC. Maternal near miss towards standard tool for monitoring quality of maternal health care. Best Pract Res Clin Obstet Gynaecol. 2009;23:287-96.

5. Souza JP, Gülmezoglu AM, Carroli G, Lumbiganon P, Qureshi Z. WHOMCS research group. The World Health Organization multicountry survey on maternal and newborn health: study protocol. BMC Health Serv Res. 2011;11:286.

6. Prual A, Bouvier- Colle Bernis L, Breat G. Severe maternal morbidity from direct obstetric causes in West Africa: incidence and case fatality rates. Bull World Health Organization. 2000;78:593-602.

7. Waterstone $\mathrm{M}$, Bewley $\mathrm{S}$, Wolfe $\mathrm{C}$. Incidence and predictors of severe obstetric morbidity: case-control study. BMJ. 2001;322;1089-94.

8. Baskett TF, Sternadel J. Maternal intensive care and near miss mortality in obstetrics. Br J Obstet Gynaecol. 1998;105(9):981-4.

9. Dias de Souza JP, Duarte G, Basile-Filho A. Near-miss maternal mortality in developing countries. Eur J Obstet Gynecol Reprod Biol. 2002;104(1):80.

10. Mantel GD, Buchmann E, Rees H, Pattinson RC. Severe acute maternal morbidity: a pilot study of a definition for a near-miss. Br J Obstet Gynaecol. 1998;105(9):985-90.

11. Souza JP, Cecatti JG, Haddad SM, Parpinelli MA, Costa ML, Katz L, et al The WHO maternal near-miss approach and the maternal severity index model (MSI): tools for assessing the management of severe maternal morbidity. PLoS One. 2012;7(8):e44129.

12. Nath A. India's progress towards achieving the millennium development goals. India K Comm Med. 2011;36(2):85-92. 
13. Lewis G. The confidential enquiry in to maternal and child health (CEMACH). Saving mothers lives: reviewing maternal deaths to make mother hood safer 2003-2005. The seventh report on Confidential Enquiries into Maternal deaths in the United Kingdom. London: CEMACH; 2007.

14. Adeoye IA, Ijarotimi OO, Fatusi AO. What are the Factors That Interplay from normal pregnancy to near miss maternal morbidity in a nigerian tertiary health care facility? Health Care Women Int. 2014:1-18.

15. Purandare CN. Maternal near miss review: a way forward. J obstet Gynaecol India. 2013;63(4):213-5.

16. Morse ML, Fonseca SC, Gottgtroy CL, Waldmann CS, Gueller E. Severe maternal morbidity and near misses in a regional reference hospital. Rev Brass Epidemiol. 2011;14(2):310-22.
17. Verma S, Rai L, Kumar P, Pai MV, Shetty J. "Nearmiss" obstetric events and maternal deaths in a tertiary care hospital: an audit. J Pregn. 2013;2013:393758.

18. Goffman D, Madden RC, Harrison EA, Merkatz IR, Chazotte C. Predictors of maternal mortality and near miss maternal morbidity. J Perinatol. 2007;27(10):597601.

Cite this article as: Suhurban SA, Nambisan B, Lekshmikutty ST, Brahmanandan M, Radha S. Determinants of near miss mortality in a tertiary care centre. Int J Reprod Contracept Obstet Gynecol 2017;6:470-8 